\title{
Development of Mathematics Competences in Higher Education Institutions
}

\author{
http://dx.doi.org/10.3991/ijep.v3iS2.2394 \\ Anda Zeidmane \\ Latvia University of Agriculture (LUA), Jelgava, Latvia
}

\begin{abstract}
The changes in society require revision of the content of higher education. Mathematics as a classical subject has played an important part in higher education until now, especially in engineering education. The introduction of mathematics IT programmes (MathCad, MathLab, Matematica, Maple...) in labour market caused the reduction of the practical application of the classical mathematics, therefore it is important to draw attention to the development of mathematical competences. The theoretical part of the paper deals with the notion of competence, its aspects and types, considers the question of the essence of mathematics, examines general competences driven teaching of mathematics, describes organisational model underlying the curriculum in mathematics that is based on the division of the content of mathematics into levels. The paper describes the main issues of the development of teaching of mathematics discussed by European mathematicians (SEFI Math Working Group). The paper presents the results of the ERDF project "Crossborder network for adapting mathematical competences in the socio-economic development (MatNet)", which studied the role of mathematics in today's labor market in the context of modern education ("Mathematics in professional activities") and the role of mathematics in studies at the Latvia University of Agriculture (LUA) and Siauliai University in Lithuania ("Mathematics in professional studies"). The paper describes the LUA experience in integration of IT programmes in the study process of mathematics, as well as the experience of organizing the selfdirected study of mathematics' practical application based on didactic approach and e-learning features.
\end{abstract}

Index Terms-mathematics competences, mathematics study, improvements of math study programs

\section{INTRODUCTION}

Contemporary education has to fulfill many tasks required by modern trends in the development of society. This process has caused urgent needs to change the education environment. Mathematics is involved in this process therefore it is important to examine the role of mathematics in the present education, especially engineering education. The following questions should be revised again: What is Mathematics?, What is the purpose of teaching Mathematics?, What do we want students to do with their understanding?

The problem is that mathematics must appear understandable and relevant and be of practical use in the adults' living world. However, the subject of mathematics is often represented as a long succession of facts to be memorized and reproduced. Many research findings show that the "school mathematics" and mathematics that are actually used or needed in a range of life situations are not related.

Besides, different mathematical IT programmes are applied in solving different mathematical problems. Due to this reason many stakeholders hold the view that students should not be "tortured" with complicated calculations in higher mathematics - it would be enough if they would learn the main notions and use the relevant programmes in problem solution.

Meanwhile, the situation in the labour market is dynamic: new products are launched, production management system, equipment, technological processes etc. change persistently. Therefore the system of higher education cannot provide an individual with the knowledge necessary during the whole professional life. Universal and sustainable knowledge and skills are significant both for university and for production that will be useful in diverse forms of professional activities in the long-term period [1].

Therefore the development of competences driven teaching of mathematics cannot be ignored, which, firstly, fosters general cognitive development supporting long-life learning.

\section{Problem of Research}

The problem of the research is to study general competences driven teaching of mathematics, to study mathematics' role in today's labor market, in the context of modern education. The aim is to develop recommendations for improvements of mathematics study programs for development of mathematics competences.

\section{MATERIALS AND METHODS}

In order to study general competences driven teaching of Mathematics, the definition of competences, its aspects and main types will be described.

Many definitions of competences exist in the scientific literature. The term "competence" includes multi-form semantic meaning. It is developed from the German word "kompetenz". One of the meanings is a wide range of knowledge and understanding in a definite sphere or question. In Latin the word is "compete" that means to be useful and adequate [2]. Today competence is defined also as a combination of knowledge, skills and experience that manifests itself in activities [3].

Competences have multiform aspects. One of the most important of aspects is the relation to the development of the personality. It underlines that learning through doing is an essential feature of competence. Another is the global aspect: sustainability, postmodern society, democracy, globalization, environment protection, quality of life, 


\section{DEVELOPMENT OF MATHEMATICS COMPETENCES IN HigHER EDUCATION INSTITUTIONS}

human ecology, life-long learning etc. Sustainability is the basic principle of the European Union and it is characterized more detailed in the Declaration on Guiding Principles for Sustainable Development.

Scientific literature offers many kinds of competences. Based on the analysis of scientific literature the authors Malinovska L., Zeidmane A., Abele J. [4] have developed a diagram to classify the kinds of competences "Fig. 1".

It is significant to research the notion of mathematics in this context, to find out what competences are developed by mathematics, what is the share of these competences among the general competences of personality.

Mathematics is a multi-faceted subject, and a unique construction of human thought. Despite its high degree of abstraction, the subject has many deep and living connections with our daily world, in both simple everyday events and advanced scientific matters. Mathematical models are embedded in technical and social artifacts and are thus generally invisible to ordinary people. Mathematics is also a domain for a particular kind of aesthetic experience, it provides moments of clarity and beautiful patterns that can create highly euphoric feelings of unexpected insight and overall understanding [5].

SEFI (European Society for Engineering Education) Mathematics Working Group suggests the following definition: "Mathematics is at the heart of engineering, being both a language for the expression of ideas and the means of communicating results. An effective study programme in mathematics for all engineering students is a necessary requirement for the education of qualified engineering graduates capable both of innovation and of adaptation to changing technology." [6]

Three forms of insights into and judgements about mathematics are the following:

- The specific uses of mathematics in other subject and practice areas,

- The historical developments of mathematics, internally as well as in societal contexts,

- The character of mathematics as a subject.

Kjeld B Laursen [7] cooperating with Institute of Mathematical Sciences, Centre for Science Education, University of Copenhagen designs the eight mathematics competences "Fig. 2".

Mathematical thinking competence means mastering mathematical modes of thought. It is competence of awareness of the types of questions that characterize mathematics, of ability to pose such questions and insight into the types of answers that can be expected.

Problem handling competence means being able to formulate and solve mathematical problems, i.e. put forward (detect, formulate, delimitate and define) different kinds of mathematical problems, pure and applied, open and closed. It is competence to solve mathematical problems, if already formulated, whether posed by oneself or by others, and, if necessary or desirable, in different ways.

Modelling competence means being able to analyze and build mathematical models concerning other areas, i.e. able to: 1) analyze the foundations and properties of existing models and being able to assess their range and validity; 2) perform active modelling in a given context, i.e. mathematizing and applying it to situations beyond mathematics itself.

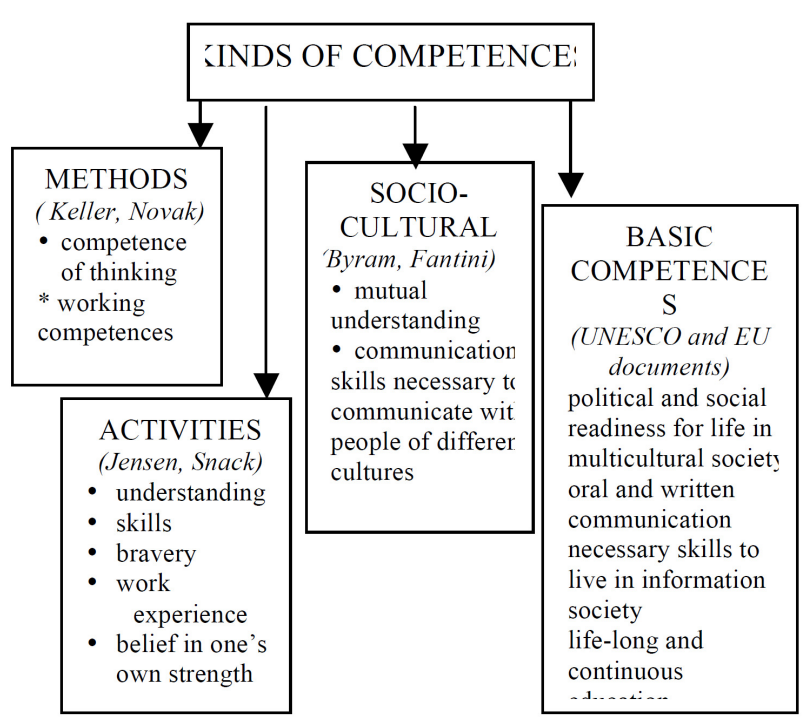

Figure 1. Kinds of Competences

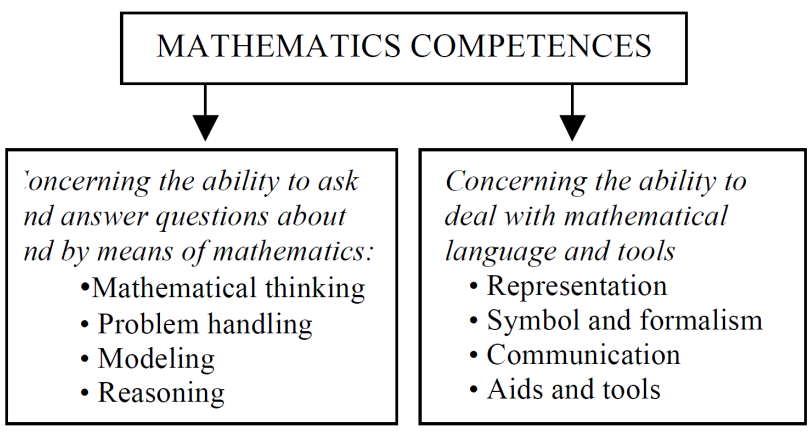

Figure 2. Mathematics Competences

Reasoning competence means being able to reason mathematically: 1) the ability to follow and assess mathematical reasoning, i.e. a chain of arguments put forward by others, in writing or orally, in support of a claim; 2) the ability to produce and carry through informal and formal reasoning (based on intuition); including transforming heuristic arguments into formal, correct proofs

Representation competence means being able to handle different representations of mathematical entities: 1) understand (i.e. decode, interpret, distinguish between) and utilize different kinds of representations of mathematical objects, phenomena, problems or situations (including symbolic, algebraic, visual, geometric, graphic, diagrammatic, tabular or verbal representations, but also concrete representations of material objects); 2) understand the reciprocal relations between different representational forms of the same entity, as well as knowing about their strengths and weaknesses, incl. loss or increase of information.

Symbols and formalism competence means being able to handle symbols and formal mathematical language, i.e. to: 1) decode symbol and formal language; 2) translate back and forth between mathematical symbol language and natural language; 3) treat and utilize symbolic statements and expressions, including formulas.

Communication competence means being able to communicate in, with, and about mathematics, i.e. to: study and translate written, oral or visual mathematical expressions or texts, and express oneself in different ways and with different levels of theoretical or technical precision 
about mathematical matters, either written, oral or visual, to different types of audiences

Aids and tools competence means being able to make use of and relate to the aids and tools of mathematics (incl. IT), i.e.: 1) know about existence and properties of relevant tools used in mathematics; 2) have insight into their possibilities and limitations; 3) be able to use such aids reflectively.

The above mentioned competences can be obtained by studying mathematics as a subject. The higher mathematics is included in many study programmes, but with different amount of ECTS. There is a tendency to decrease the amount of ECTS. Consequently, it is important to consider the development opportunities of mathematics curriculum, incorporating various levels in it, especially in engineering education. In 2002 SEFI Document created by L.R. Mustoe and D.A. Lawson "Mathematics for the European Engineer" was published [8] which contains the organisational model underlying the curriculum in mathematics "Fig.3".

Core Zero - the knowledge and abilities the students entering the higher education should have. It contains topics from algebra, analysis and calculus, discrete mathematics, geometry and trigonometry, statistics and probability.

Core One - the material which is understood as a basis for all engineers even though the difference between different branches of engineers (especially computer science engineers) is mentioned and understood.

Core Two - more advanced topic in mathematics ("Electives"). This is not meant as necessary for every engineering student but serves as a source for advanced material to different engineering branches that are more mathematics based.

Core Three - special topics usually taught within engineering courses rather than in special mathematics ones ("Specialist Modules").

The following topics are still discussed in the development of mathematics education: Transition from school to university, Contents and learning outcomes, Higher-level learning goals, assessment, Activation of learners, Use of technology, Modeling competencies and their teaching, Integration of mathematics and engineering subject education, Students' attitudes towards mathematics, Mathematics at the workplace, Mathematical needs in continuing engineering education, Mathematical education research [9].

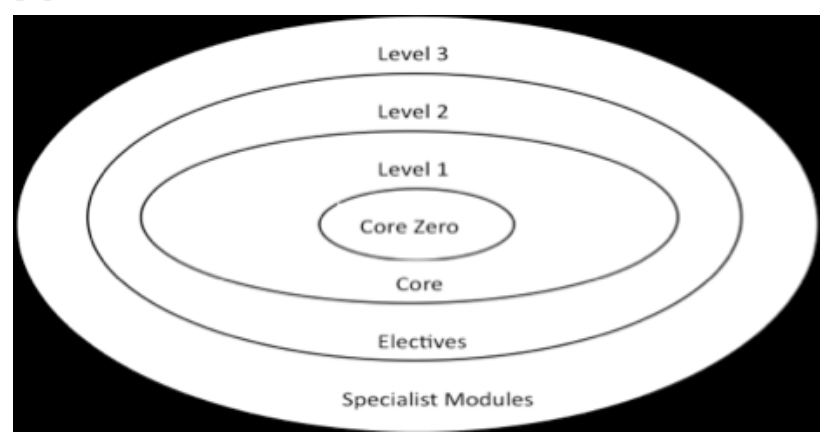

Figure 3. Organisational model underlying the curriculum (according to L.R.Mustoe and D.A. Lawson)

\section{RESULTS AND DISCUSION}

The ERDF project "Cross-border network for adapting mathematical competences in the socio-economic development (MatNet)" [10] is implemented since 2011 by the Departments of Mathematics of the Latvia University of Agriculture and Siauliai University in Lithuania to research the development opportunities of mathematical competences. The first year of the project was devoted to the internal and external research (see Fig. 4)

The external research included the analysis of regional strategic plans and other national documents and the questionnaire was designed and uploaded in the project website - "Mathematics in professional activities" in the English, Latvian, and Lithuanian languages „Fig. 5“. More than 300 employers and employees from Latvia and more than 200 employers and employees from Lithuania participated in the survey.

More than $65 \%$ employees consider that mathematics gives an insight into the world; more than $72 \%$ consider that mathematics develops thinking, helps to make a decision in a particular situation and find new ideas, but more than $79 \%$ consider that mathematics helps to model and analyze the problems of the real world "Fig.6".

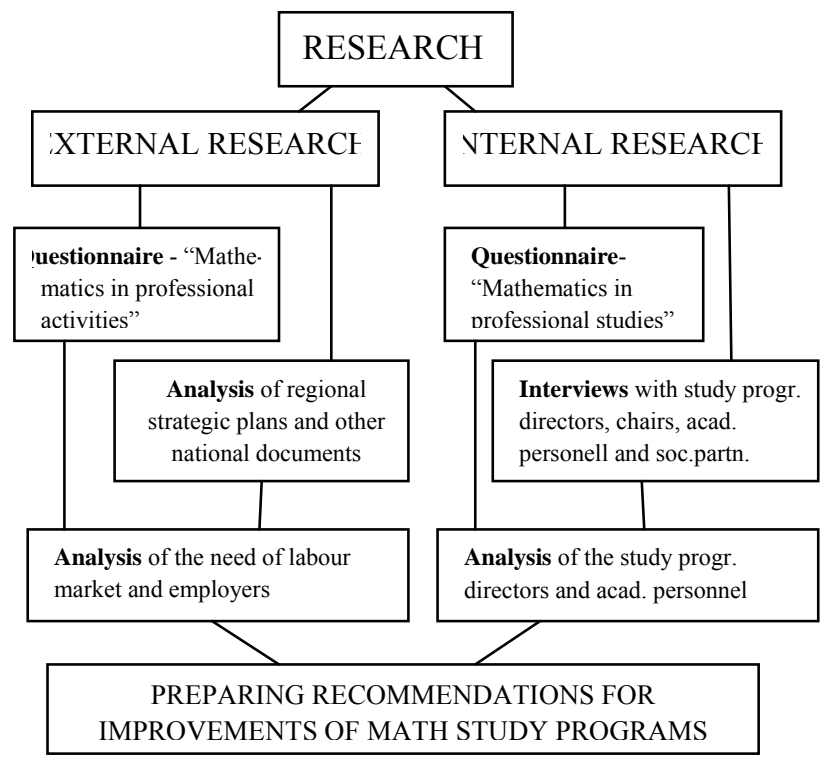

Figure 4. Areas of the project research

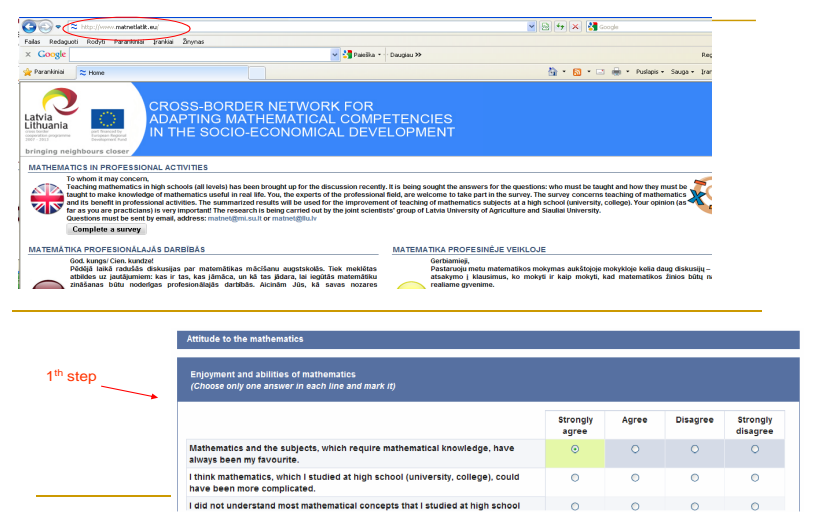

Figure 5. Cross-Border project website 


\section{DEVELOPMENT OF MATHEMATICS COMPETENCES IN HIGHER EDUCATION INSTITUTIONS}

At the same time more than $22 \%$ consider that mathematics means only formulas that are necessary to remember and about $20 \%$ consider that mathematics is a meaningless game with numbers which is played according to the rules created by scientists.

As regards the mathematics in professional activities, $52 \%$ of respondents consider that mathematics is widely used in their professional activities, but $48 \%$ consider that their occupation does not require deeper knowledge of mathematics: it is enough to do arithmetical calculations and count percentage "Fig.7". 59\% of respondents consider that mathematical thinking helps to solve real professional problems. It is gratifying to note that more than $61 \%$ recognize that people who understand mathematics well, are highly assessed by employers.

The evaluation of employers of mathematics teaching at universities in Latvia and Lithuania caused great interest "Fig.8". Only about 50\% of employees consider that Math was an interesting and meaningful subject. It is not a pleasant fact that $62 \%$ admit that most of students did not understand mathematics and tried to learn rules by heart, and $47 \%$ - mathematics was taught in matter-of-fact and boring way. Besides, $61 \%$ of respondents agree with the statement that studying mathematics at university was wasting of time and that knowledge got in secondary school is enough (39\% -disagree). The positive side of this block is that more than $65 \%$ consider that mathematics knowledge helped them to understand other study subjects and more than $76 \%$ consider that studying mathematics developed logical thinking accuracy and concreteness of future specialists.

During internal research the interviews were carried out with the programme directors, academic personnel, social partners. The majority of them recognize the role of mathematics in the development of logical thinking, but, unfortunately, study programmes have ECTS restrictions and directors of study programmes are interested to give more ECTS to special subjects and less ECTS to general subjects, including mathematics. Unfortunately, the survey showed that the majority of lecturers hardly ever apply higher mathematics in the special subjects. The

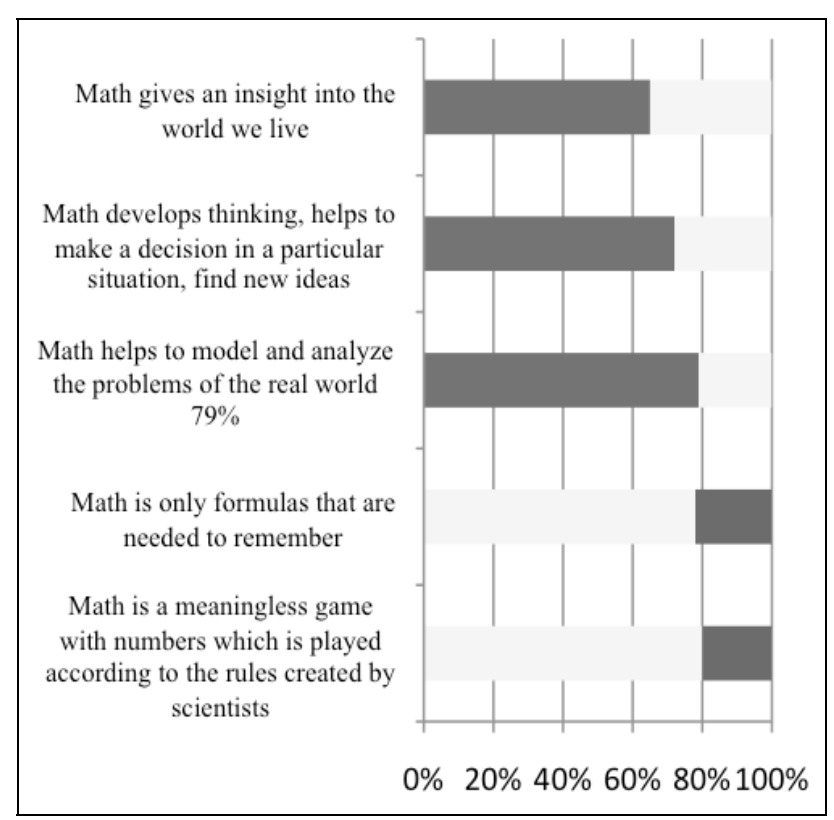

Figure 6. Assessment of practical potential of Mathematics "ready-made" formulas are analyzed and respective processes described. Meanwhile, lecturers are disappointed with students' basic knowledge in mathematics which are mostly necessary to perform calculations.

Directors of study programmes and lecturers recommended the following for the development of mathematical competences: 1) further integration of IT programmes in mathematics study process (MathCad and MathLab); 2) the emphasis on the applicability of mathematics.

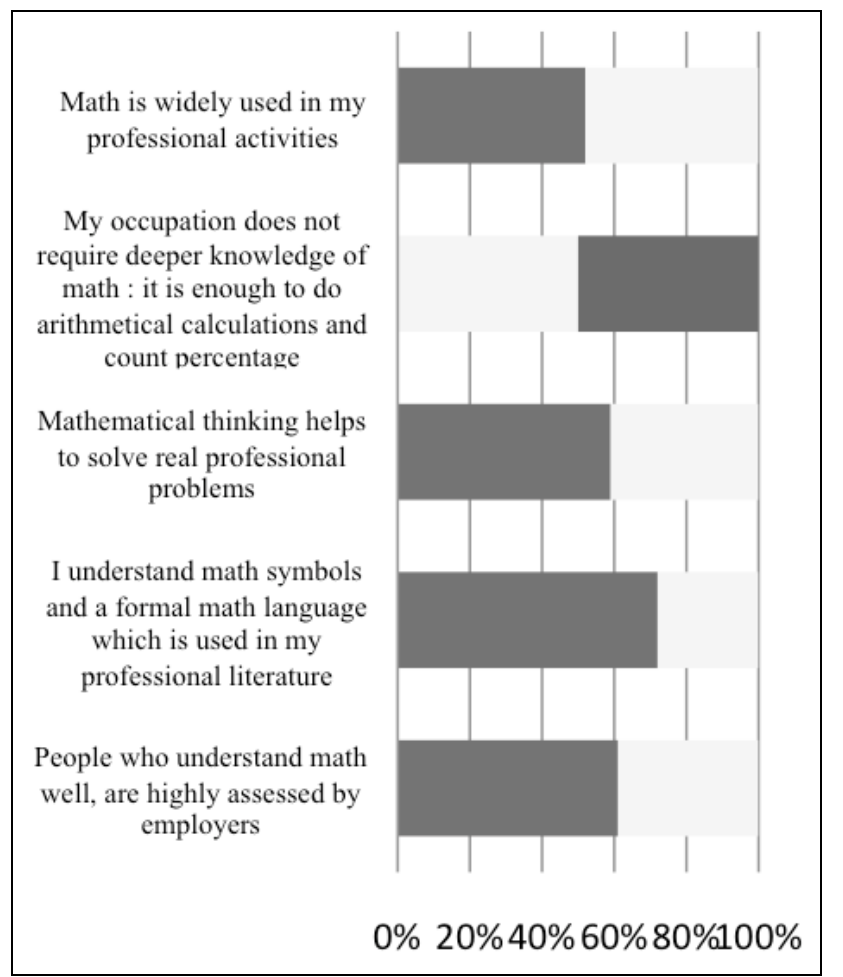

Figure 7. Mathematics in professional activities

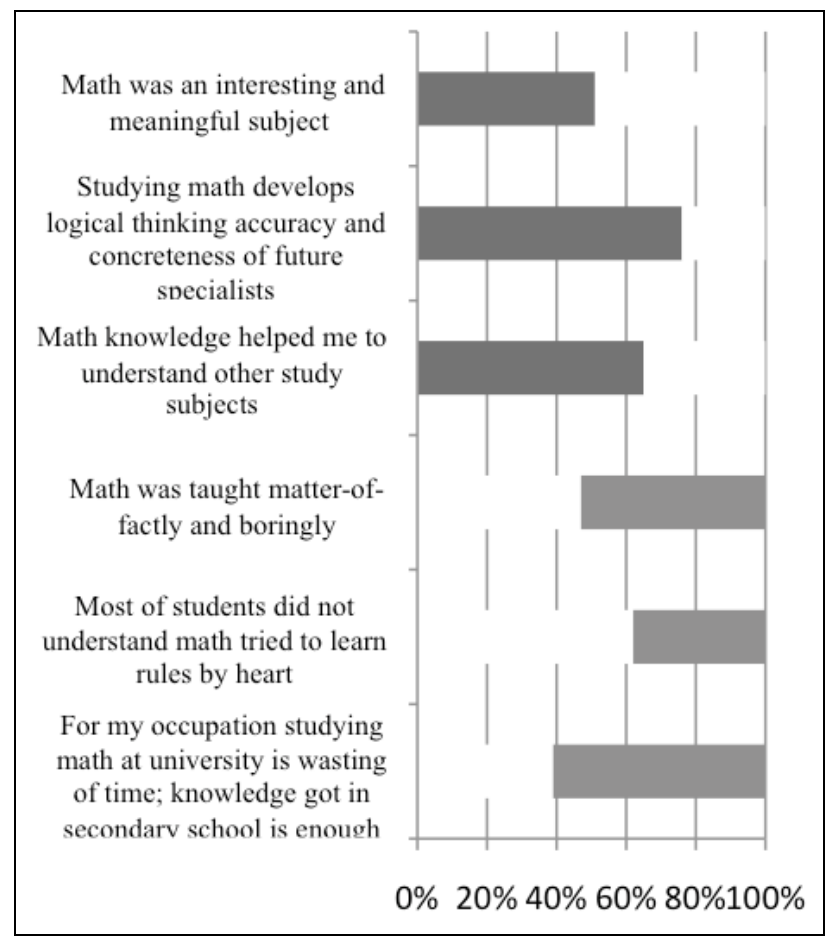

Figure 8. Mathematics teaching at universities 
The developed recommendations for the improvement of mathematics study programs emphasized that a compromise should be found between the acquisition of the fundamental knowledge, acquisition of know-how application of knowledge as well as the use of IT software in the calculations. Many colleagues concentrate mainly on the education of "users", because they think that the most important thing is to teach students to perform the necessary calculations. However, what is the main objective of the university: should students be taught "how to do it?" (the author thinks that it is the task of secondary technical schools) or should students be taught "why should it be done?". The latter requires serious theoretical studies of the respective subjects which require mathematical demonstrations that develop cognitive abilities and provide with understanding of interconnections. Likewise, we cannot ignore the achievements of IT and neglect the skills of software application with the help of which rapid calculations are possible.

Mathematics department in the LUA have good experience in integrating IT program MathCad in mathematics study process for bachelor and MathLab for master programmes, accounting for 0.5 of contact lessons per week as laboratory work.

Teacher of MathCad in cooperation with the teacher of the practical work hand out homework to students about corresponding topic which they must solve on the paper, showing the process of solving step by step, afterwards in the practical classes students check solutions themselves using MathCad programme. The analysis of the students' success and the students' survey at the LUA shows that students prefer the introduction of MathCad in the study subject of mathematics instead of learning MathCad as a separate subject supplied by mathematical examples. Students enjoy comparing the results of their individual tasks with the results obtained via MathCad, that, in turn, increase the motivation to solve more mathematic problems, since students are interested in solving several variants. The final tests complete the study period of individual tasks and MathCad problems thus the final tests show the improved scores.

As regards the recommendations of the academic staff to include mathematics applications in the study process, the two-fold impact of mathematics in education, direct and indirect impact, should be explained. "Fig 9".

Figure 10 shows the solution path of the engineering problems and the necessary knowledge of mathematics in the problem solving phase.

As the diagram shows, the definition of engineering problem requires knowledge in the respective engineering science. If the teaching is performed by mathematics teacher, he/she as a nonprofessional should explain technical concepts which are taken out of context and therefore they are not well understood by students, since mathematics is included in the $1^{\text {st }}$ and $2^{\text {nd }}$ year of the curriculum un students now little about their speciality. The second problem is the reduced number of ECTS in mathematics and there is no time to solve practical mathematical tasks.

One of the solution of the problem could be the application of e-environment, but it is connected with students' self-directed study. It is very important to find the way how to organize the self-directed study of mathematics' practical application based on didactic approach and e-

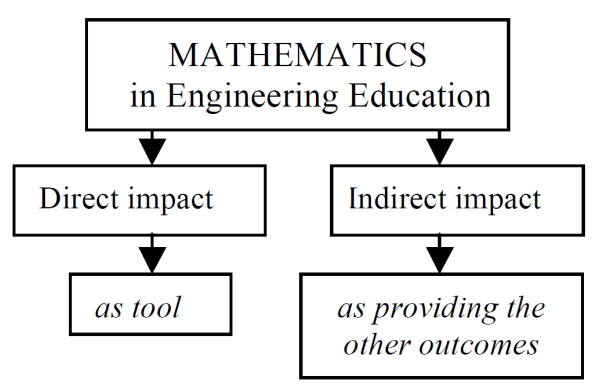

Figure 9. Mathematics impact in Engineering Education

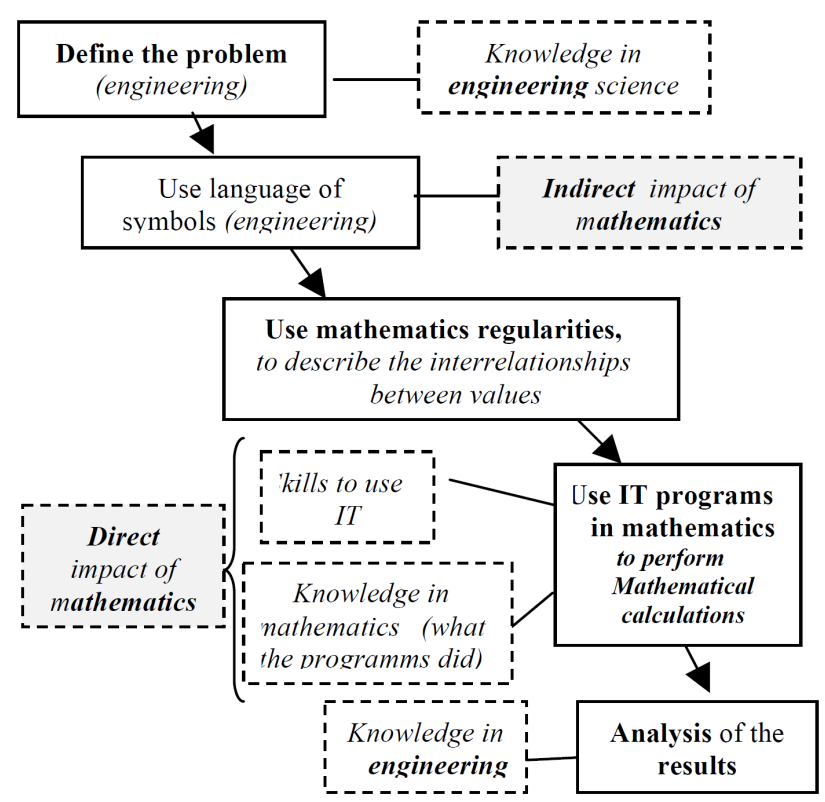

Figure 10. Mathematics impact in Engineering Education

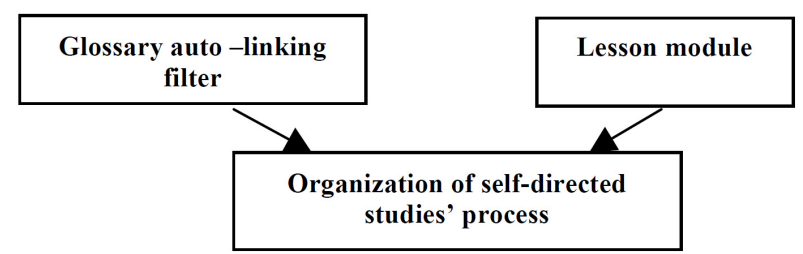

Figure 11. Moodle's tools for organization of self-directed studies' process

learning features. To achieve this goal, the LUA chose Moodle computerized learning system (CMS), which is one of the largest e-learning systems [11]. At the LUA this system is used as e-learning tool since September, 2010. Moodle has two main tools for problem's solution mentioned before - glossary auto-linking filter and lesson module "Fig.11".

The Glossary activity is one of the Moodle features which can store list of definitions for specific terms, it is like vocabulary. Glossary auto-linking filter is creating links to glossary activity entry where the word or phrase of the glossary entry is used within the same course in which glossary is located [12]. When this setting is turned on, whenever a word from a Glossary appears in the course, it is highlighted in gray. Clicking on the word brings up a pop-up window containing the word's Glossary entry. The lesson module presents a series of HTML pages to the student who is usually asked to make some sort of choice underneath the content area [13]. The choice 
will send them to a specific page in the Lesson. In a Lesson page's simplest form, the student can select a continue button at the bottom of the page, which will send them to the next page in the Lesson.

For understanding practical application of mathematics it is necessary to have additional knowledge in specific terms and regularities. Mathematics teacher in cooperation with the special subject teacher create glossary autolinking filter, which contains those terms and laws that will be taught in later on in the respective special subjects.

Lesson module with scenario based steps and links to created glossary has been made for successful organization of self-directed studies, so that students can independently solve the problems using knowledge in mathematics "Fig. 12".

At first, the student receives a practical problem from which it must express picture and task related values. If he/she has a problem to solve this step, he/she can get answer for each step separately. Problem must be formulated by picture, terms and symbols and separate known from unknown values. After problem formulation the student has to express regularities for unknown values, respectively, the help with included answer can be received.

In this step just general regularities are expressed, but students must judge problem specific regularities independently, again if is there is some problem for this solving, extra answers (Answer 4 and 5) can be received. When regularities are obtained, it is necessary to choose a correct solution method, in any case the student has an access to Answer 6, where correct mathematical method is given. Then it is necessary to find out relationship between obtained and given known value, therefore extra regularities are provided (Answer 7..n) for extra support. Next mathematical calculation is followed which will give a problem solution for the student, mathematical calculation is supported with suggestions and mathematical methods.

\section{CONCLUSION}

Mathematics is a multi-faceted subject, and a unique construction of human thought. According to SEFI: "Mathematics is at the heart of engineering, being both a language for the expression of ideas and the means of communicating results".

People can develop eight general competences driven teaching of mathematics, which can be grouped in to groups: 1) competences concerning the ability to ask and answer questions about and by means of mathematics (mathematical thinking, problem handling, modeling, reasoning) 2) competences concerning the ability to deal with mathematical language and tools (representation, symbol and formalism, communication, aids and tools).

Summarizing the results of ESF project "Cross-border network for adapting mathematical competences in the socio-economic development (MatNet)" external research about mathematics' role in today's labor market in the context of modern education, a conclusion can be made that more than $70 \%$ of employees consider that mathematics gives an insight into the world, develops thinking, helps to make a decision in a particular situation. As regards the mathematics in professional activities, only about $50 \%$ of respondents consider that mathematics is widely used in their professional activities, but approxi-

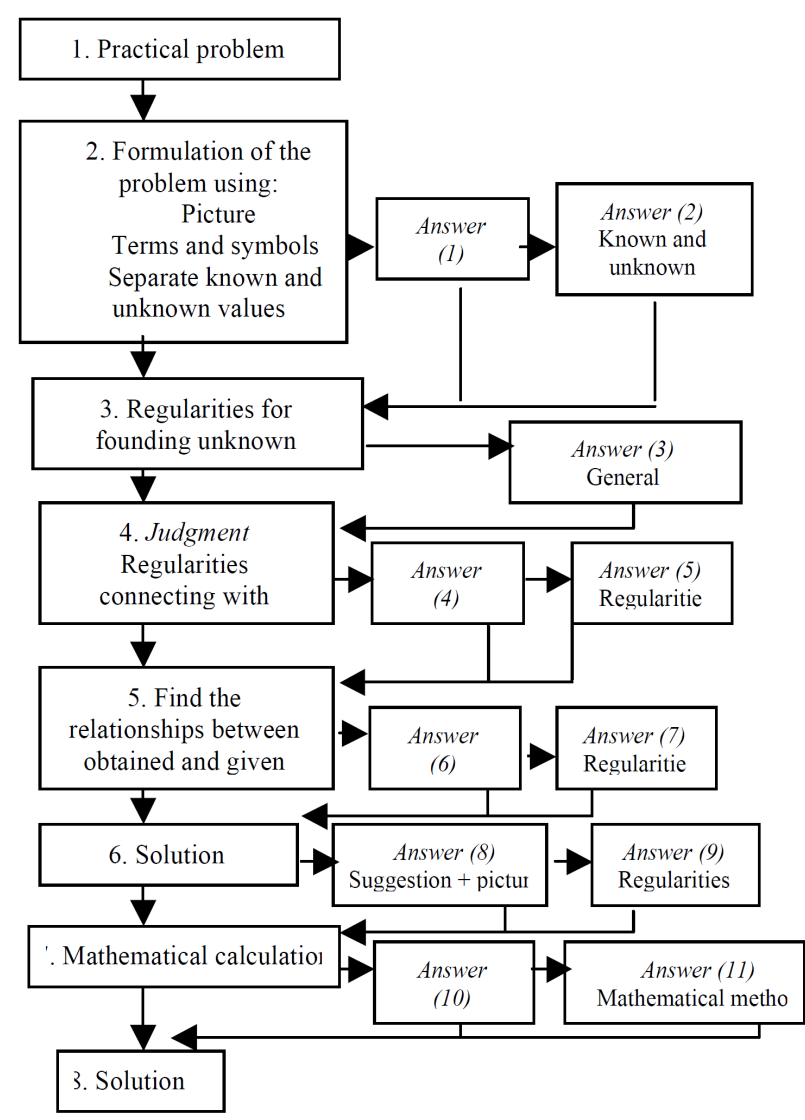

Figure 12. Framework for organization of practical problem solving in mathematics (didactical steps)

mately $60 \%$ of respondents consider that mathematicalthinking helps to solve real professional problems. Concerns are caused by the result that only about $50 \%$ of employees consider that mathematics at universities was an interesting and meaningful subject and approximately $60 \%$ recognize that most of students did not understand mathematics and tried to learn rules by heart.

During internal research the interviews were carried out among directors of study programmes, academic personnel, social partners, whose recommendations for the improvement of mathematics programmes were the following: 1) further integration of IT programmes (MathCad and MathLab) in mathematics study process; 2) the emphasis should be on the applicability of mathematics.

The above mentioned recommendations were implemented in the mathematics study process at the LUA. IT programme MathCad was integrated in mathematics study process for Bachelor and MathLab for Master study programmes, accounting for 0.5 of contact lessons per week as laboratory work. With regards to mathematics application the problems are: 1) that mathematics study is included in the $1^{\text {st }}$ and $2^{\text {nd }}$ year of the programme when the students have insufficient knowledge in their special subjects; 2) mathematics teacher as a nonprofessional should explain technical concepts which are taken out of context and therefore they are not well understood by students; 3 ) the number of ECTS in mathematics is reduced and there is no time to solve practical mathematical tasks. The solution of the problems is to organize the self-directed study in e-environment with mathematics' practical application based on didactic approach and e-learning features. 


\section{DEVEloPMENT OF MATHEMATICS COMPETENCES IN HigHER EDUCATION INSTITUTIONS}

\section{REFERENCES}

[1] A. Zeidmane, S. Čerņajeva (2011) Interdisciplinary Approach in Engineering Education. International Journal of Engineering Pedagogy iJEP. Vol 1, No1. online-jornals.org/index.php/i-jep/

[2] Dictionary of Foreign Words, Comp. by Baldunčiks J. and Pokrotniece K. Rīga: Jumava.1999

[3] I. Maslo, I.Tilı̧a (2005) "Competence as an Ideal of Education and Analytical Category”. Skolotājs, vol 3, Rīga,: Zvaigzne, 2005., pp 4-9.

[4] L. Malinovska, A. Zeidmane, J.Abele “ Different Aspects and Levels of Competences", Proceedings of the $1^{\text {st }}$ International Conference on Strategic Development of the baltic Sea Region (BSR), 2003 http://ikarus.e-technik.fh-kiel.de/bsn42/index.php?id=45

[5] L. Gustafsson, L. Ouwitz (2004) „Adults and Mathematics - a vital subject”. ISSN 1650 -335X, NCM, 2004.

[6] SEFI Mathematics Working Group. http://learn.lboro.ac.uk/mwg/.

[7] K. B. Laursen (2009) "Competence driven teaching of mathematics". Publish by Institute of Mathematical Sciences, Centre for Science Education, University of Copenhagen, [competences_mathematic_pdf] P.13

[8] L. R. Mustoe, D. A. Lawson (2002) „Mathematics for the European Engineer - A curriculum for the twenty first century". SEFI Document, March 2002.

[9] B. Alpers, M. Demlova (2010), The SEFI Math Working Group Resources and future plans". Proccedings of 15th SEFI_MWG European Seminar on Mathematics in Engineering Education. http://sefi.htw-

aalen.de/Seminars/Wismar2010/SEFI/paper_pdfs/MWG2010

[10] S. Balciunas, R. Macaitiene, Virgailete-Meckauskaite, A. Vintere, A. Zeidmane, N.Paulins (2011). " Development of Mathematical Competencies in Higher Education Institutions within SocioEconomical Context". Publishing House of Siauliai University. N., $\begin{array}{lll}\text { ISBN } & 978-609-430-063-9 . & \text { P.211 }\end{array}$ http://www.iipc.lv/saite1/petijums.html

[11] J.A.B. Lahins, T.A.M Ezis (2010) "Experience of Moodle Ale System Implementation and Comparison with Computerized Tests and other CMS Alternatives". Proceedings of the 4-Th International Scientific Conference, pp.188-192.

[12] Glossary auto-linking filter. Moodle docs web page, Available at: http://docs.moodle.org/20/en/Glossary_auto-linking_filter [Accessed December 28, 2011].

[13] Lesson module. Moodle docs web page, Available at: http://docs.moodle.org/22/en/Lesson_module [Accessed December 28, 2011].

\section{AuTHORS}

A. Zeidmane is the Head of the Department of Mathematics, Latvia University of Agriculture, Latvia (e-mail: anda.zeidmane@1lu.lv)

This article is an extended and modified version of a paper presented at the International Conference on Engineering Pedagogy (IGIP2012), held 26 - 28 September 2012, in Villach, Austria. Received 29 November 2012. Published as resubmitted by the authors 27 February 2013. 